\title{
0 problema do 1 Coríntios 11,1-6 e a questão de gênero na igreja de Corinto
}

The problem of 1 Corinthians 11.1-6 and the gender issue in the

\section{Roberta Alexandrina da Silva*}

Resumo: Este artigo analisa a questão de gênero dentro da igreja de Palavras-chave: Corinto e como o cognominado "Apóstolo dos gentios", Paulo de Tarso, elaborou um discurso para debater estas questões. Concomitante a isso, far-se-á uma discussão sobre comportamentos e posturas dentro do Império Romano referentes à indefinição entre as categorias de masculino e feminino.

Paulo de Tarso;

Corinto;

Discurso;

Gênero;

Profetisas.

Abstract: This article examines the issue of gender debates within the Keywords:

Church of Corinth and how Paul of Tarsus, the so-called "Apostle of the Paul of Tarsus; Gentiles, build a speech to discuss these issues. Concomitant this, we Corinth; intend to study the parallel, within the Roman Empire, between behaviors and attitudes regarding the male and female roles.

Discourse;

Gender;

Prophetesses

* Doutora e mestra em História pela Universidade Estadual de Campinas. Pofessora da Universidade Federal do Pará. 
$\mathrm{U}$ ma das figuras mais idiossincrásicas do movimento cristão nos seus anos iniciais foi Paulo de Tarso. Para James D. G. Dunn, na obra $A$ teologia do Apóstolo Paulo, a importância de Paulo é ímpar como o "primeiro e o maior teólogo cristão" (DUNN, 2003, p. 25-26). Conforme o autor, a influência teológica de Paulo nos séculos posteriores foi crucial, pois

Paulo foi 'primeiro' no sentido de ser preeminente entre os teólogos cristãos. Ele pertenceu àquela geração que foi mais criativa e mais definitiva para a formação e a teologia do cristianismo do que qualquer outra desde então. $\mathrm{E}$ nessa geração ele mais do que qualquer outra pessoa contribuiu para que o novo movimento originário de Jesus se tornasse religião realmente internacional e intelectualmente coerente. Paulo foi efetivamente chamado o 'segundo fundador do cristianismo', que, 'em comparação com o primeiro, exerceu, sem dúvida alguma, a influência... mais forte'.

A despeito do entusiasmo excessivo de James Dunn, expresso no trecho acima, é impossível negar que a influência dos escritos de Paulo sobre o cristianismo foi maior do que os escritos e a teologia de qualquer outro pensador cristão. A teologia paulina foi tão significativa, particularmente, para a formação da Igreja nos séculos posteriores que podemos perceber a influência dela em Clemente de Roma, Inácio de Antioquia e Irineu de Lyon. Na Antiguidade Tardia, Agostinho reafirmou a teologia cristã paulina, que dominou a maior parte da Idade Média. Além disso, foi predominantemente o alcance da teologia de Paulo que moldou a Reforma. Já no período moderno alguns autores, como F. C. Baur (1878) e Karl Barth (2009), atestaram a mesma influência formativa.

Percebe-se, assim, que várias gerações de teólogos cristãos refletiram sobre a teologia paulina. Com isso, compreendemos que a análise dos escritos paulinos foi crucial para a fundamentação da exegese feminista no meio teológico, em especial a abordagem de Elisabeth Fiorenza (1992). Outro autor que compartilha das considerações de James Dunn é o teólogo Bart D. Ehrman, que fez a seguinte observação:

Será que já existiu uma figura cristã tão controvertida quanto o apóstolo Paulo? Foi uma nova compreensão das Cartas de Paulo que levou Martinho Lutero a afastar-se da Igreja Católica, levando à Reforma Protestante e a uma divisão da Cristandade que continua até hoje. Igrejas de todo tipo continuam a discutir os ensinamentos de Paulo: algumas insistem em que seus textos proíbem que as mulheres sejam ordenadas presbiteras, ao passo que outras denominações 
insistem justamente no contrario; alguns alegam que suas cartas denunciam as relações homossexuais, e outros afirmam o contrário; alguns argumentam que suas cartas apoiam as formas ocidentais de capitalismo, outros dizem justamente o oposto (ERHMAN, 2008, p. 139, grifo nosso).

A argumentação de Ehrman demonstra como Paulo inspira controvérsias na atualidade, sendo crucial para a negação e justificação da submissão feminina dentro do espaço eclesial. Os escritos de Paulo pesam muito em qualquer debate acerca do lugar da mulher na vida e no ministério da Igreja. Não seria exagero dizer que a literatura paulina se tornou o campo de combate do Novo Testamento, no qual se discutem as questões das mulheres na Igreja. Para Robin Scroggs (1972, p. 302) a questão acerca do igualitarismo entre os sexos se centra no fato de que a voz de Paulo é a única voz clara do Novo Testamento a afirmar a liberdade e a igualdade das mulheres na comunidade.

Nesse artigo, discutiremos as construções discursivas sobre Paulo e introduziremos uma abordagem a respeito dos debates de gênero, principalmente acerca do trecho do 1 Cor11, 1-16.

O trecho bíblico 1 Coríntios 11, 1-16 afirma o seguinte:

\begin{abstract}
${ }^{1}$ Sede meus imitadores, como eu mesmo o sou de Cristo. ${ }^{2}$ Eu vos louvo por vos recordardes de mim em todas as ocasiões e por conservardes as tradições tais como vo-las transmiti. ${ }^{3}$ Quero, porém, que saibais que a cabeça de todo homem é Cristo, a cabeça da mulher é o homem, a cabeça de Cristo é Deus. ${ }^{4}$ Todo homem que ore ou profetize com a cabeça coberta desonra a sua cabeça. ${ }^{5}$ Mas toda mulher que ore ou profetize com a cabeça descoberta desonra a sua cabeça; é o mesmo que ter a cabeça raspada. ${ }^{6}$ Se a mulher não se cobre com véu, mande cortar os cabelos! Mas, se é vergonhoso para uma mulher ter os cabelos cortados ou raspados, cubra a cabeça! ${ }^{7}$ Quanto ao homem, não deve cobrir a cabeça, porque é a imagem e a glória de Deus; mas a mulher é a glória do homem. ${ }^{8}$ Pois o homem não foi tirado da mulher; mas a mulher, do homem. ${ }^{9} \mathrm{E}$ o homem não foi criado para a mulher, mas a mulher para o homem. ${ }^{10}$ Sendo assim, a mulher deve trazer sobre a cabeça o sinal da sua dependência, por causa dos anjos. ${ }^{11}$ Por conseguinte, a mulher é inseparável do homem e o homem da mulher, diante do Senhor. ${ }^{12}$ Pois, se a mulher foi tirada do homem, o homem nasce da mulher, e tudo vem de Deus. ${ }^{13}$ Julgai por vós mesmo: será conveniente que uma mulher ore a Deus sem estar coberta de véu? ${ }^{14} \mathrm{~A}$ natureza mesma não vos ensina que é desonroso para o homem trazer cabelos compridos, ${ }^{15}$ ao passo que, para a mulher, é gloria ter longa cabeleira, porque a cabeleira the foi dada como véu? ${ }^{16} \mathrm{Se}$, no entanto, alguém quiser contestar, não temos este costume, nem tampouco as Igrejas de Deus.
\end{abstract}

O excerto acima é um dos trechos mais problemáticos do corpus Paulinum, pois temos uma declaração de Paulo acerca do comportamento das mulheres nas 
comunidades cristãs. Contudo, o ponto crítico seria que as mulheres, na assembleia de Corinto, estavam profetizando e orando com a cabeça descoberta, ou seja, as profetisas coríntias estavam provocando desconforto perante os demais membros devido à sua falta de decoro.

A profecia desempenhou, nas antigas comunidades cristãs, um papel importante, tanto que Paulo afirma, em 1 Cor 14, 1-5, o seguinte:

\begin{abstract}
Procurai a caridade. Entretanto, aspirai aos dons do Espírito, principalmente à profecia. Pois aquele que fala em línguas, não fala aos homens, mas a Deus. Ninguém o entende, pois ele, em espírito, enuncia coisas misteriosas. Mas aquele que profetiza fala aos homens: edifica, exorta, consola. Aquele que fala em línguas edifica a si mesmo, ao passo que aquele que profetiza edifica a assembleia. Desejo que todos falem em línguas, mas prefiro que profetizem. Aquele que profetiza é maior do que aquele que fala em línguas, ao menos que este as interprete, para que a assembleia seja edificada.
\end{abstract}

O trecho relativo a 1 Cor 11, 2-11 levanta algumas questões complexas concernentes à situação de Paulo envolvendo a disputa por autoridade. O velamento das mulheres, contudo, não foi somente uma questão de falta de decoro ou oriunda do fato de alguns membros da comunidade de Corinto se sentirem constrangidos pela atuação das mulheres, mas o próprio ato de profetizar era visto como uma experiência direta com o divino, o que concedia autoridade a quem o fizesse.

No Novo Testamento, temos referências específicas de mulheres que exerciam esta prática, como as quatro filhas virgens de Filipe (Atos 21,9) e a temida profetisa da igreja de Tiatira, Jezebel, que tinha exercido grande influência nesta comunidade (Apocalipse 2, 18-23).

Apesar do reconhecimento do papel das profetisas nas orações e nas profecias, o autor da passagem citada anteriormente (1 Cor 11, 2-11) enfoca a definição de papéis e as restrições impostas às mulheres. A explicação para a afirmação da proeminência masculina seria a seguinte: "Quero, porém, que saibas que a cabeça de todo homem é Cristo, a cabeça da mulher é o homem, a cabeça de Cristo é Deus" (v. 3).

O trecho evoca o relato da criação contido em Gênesis 2, combinado com o primeiro relato da criação, em Gênesis 1. Ora, o esquema funcionaria assim: o homem exprime a glória de Deus pessoalmente, enquanto que a mulher a do homem, como fica claro no trecho a seguir: 
${ }^{7}$ Quanto ao homem, não deve cobrir a cabeça, porque é a imagem e a glória de Deus; mas a mulher é a glória do homem. ${ }^{8}$ Pois o homem não foi tirado da mulher; mas a mulher, do homem. ${ }^{9} \mathrm{E}$ o homem não foi criado para a mulher, mas a mulher para o homem.

Além disso, a relação hierárquica é qualificada pelo reconhecimento de que a mulher dá à luz ao homem: "por conseguinte, a mulher é inseparável do homem e o homem da mulher, diante do Senhor. Pois, se a mulher foi tirada do homem, o homem nasce da mulher, e tudo vem de Deus" (vv.11,12).

A controvérsia inserida em 1 Cor 11, 2-16 reafirma o papel feminino na sociedade e, também, na comunidade de Corinto. Temos aí, contudo, um debate intenso acerca da definição de homem e mulher. Jerome Murphy-O'Connor (1980) aponta nesse sentido ao criticar os vários estudos que foram feitos sobre a perícope 1 Cor 11, 2-16, pois eles tenderam a enfatizar a figura feminina, deixando de lado o debate sobre a construção e o reforço da masculinidade. Dan W. Clanton Jr. e Margareth Y. MacDonald (1986) concordam ao afirmar que em 1 Cor 11, 2-16 houve um esforço da parte de Paulo em clarificar as noções de masculinidade e de feminilidade que deveriam ser seguidas em Corinto (CLANTON JR.; MACDONALD, 1986, p. 230).

Para MacDonald (1996), em Gálatas 3, 28 encontramos o ponto central para compreendermos essa problemática em Corinto. A abolição da distinção entre os sexos era claramente um assunto importante para se compreender as práticas dos membros nessa comunidade, pois tal distinção não era conceitual, era prática.

Anderson Dias Araújo (2008) argumenta que os coríntios estavam abolindo os sinais de diferenciação entre os gêneros, em grande parte por crerem que já estavam vivendo a escatologia realizada e, portanto, a manutenção de características que definiriam os sexos teria se tornado infundada com a nova ordem instituída pela salvação.

Observemos o excerto a seguir:

\footnotetext{
${ }^{13} J u l g a i$ por vós mesmo: será conveniente que uma mulher ore a Deus sem estar coberta de véu? ${ }^{14} \mathrm{~A}$ natureza mesma não vos ensina que é desonroso para o homem trazer cabelos compridos, ${ }^{15}$ ao passo que, para a mulher, é gloria ter longa cabeleira, porque a cabeleira lhe foi dada como véu? ${ }^{16} \mathrm{Se}$, no entanto, alguém quiser contestar, não temos este costume, nem tampouco as Igrejas de Deus (1 Cor).
} 
Percebemos, na passagem citada, que os traços que definiam o que era ser homem e o que era ser mulher são reforçados pelo discurso paulino. O sentido do véu configura-se como um entendimento de Paulo sobre a fisiologia de seu tempo, pois, ao defender o uso do véu, o "apóstolo dos gentios" acreditava que os cabelos compridos das mulheres desempenhariam a função de ser um "véu natural". Em contrapartida, os cabelos longos no homem teriam uma conotação desonrosa, de effeminatus. Para Araújo, há da parte de Paulo todo um cuidado em trabalhar dialeticamente a questão de honra e desonra quanto ao assunto do uso dos cabelos em homens e mulheres (ARAÚJO, 2008, p. 36).

Um exemplo ilustrativo para compreendermos como a subversão da ordem sexual era criticada se refere à relação que os romanos tinham com outras religiões. Ao lado do culto da deusa-mãe Cibele, havia o culto do belo jovem Átis, que, segundo a interpretação romana do mito, se havia castrado num momento de fúria provocada pela ciumenta Magna Mater. Átis morreu, mas Cibele o ressuscitou, e ele se transformou em modelo para os galli, sacerdotes da deusa que se castravam com fragmentos de algum objeto pontiagudo, vestiam-se com roupas coloridas e usavam boina e enfeites 'afeminados' nos cabelos.

Uma questão importante neste culto foi a visão que os romanos tinham em relação ao comportamento dos devotos de Cibele, ou seja, o fato de não serem homens e nem mulheres. Os autores romanos, entre eles Marcial, os desdenhavam, especialmente por causa das automutilações. Por fim, acusavam-nos de praticar sexo oral com as mulheres, apesar de serem eunucos. Marcial faz a seguinte observação:

Que você, gallus, pode fazer com o sexo de uma mulher? A sua língua deve lamber, naturalmente, o que está no meio do corpo dos homens. Por que decepou seu pênis com cacos de louça samiana, se o ânus (cunnus) é tão prazeroso para você? Sua cabeça deveria ser cortada, pois embora sendo gallus no meio das pernas, você ainda desdenha os ritos de Cibele, enquanto na boca é homem (Epigramas, 3.81).

Os galli confundiam os romanos, pois depois de sua automutilação, não eram mais capazes de manter os critérios de comportamento sexual masculino, definidos pela penetração e pelo controle sobre o parceiro. Segundo as difamações de Marcial, contudo, os galli eram capazes de se "rebaixar" a ponto de penetrarem as mulheres com a língua, prática em geral considerada degradante. Certo sacerdote da Magna Mater, 
chamado Genúcio, havia recebido uma herança, mas não teve permissão de tomar posse dela, pois não era homem e nem mulher, segundo a definição romana. Da mesma forma, assim como o comportamento sexual dos galli, o status legal de Genúcio não se adequava ao sistema legal romano a respeito do recebimento de herança (Epigr., 7.7.6).

Percebemos, assim, que os valores culturais de honra e vergonha se ancoram numa divisão nítida no campo da sexualidade. Era honroso para o homem evidenciar a virilidade da qual era portador. Era honroso ser ativo e realizar ações próprias de um varão. Ora, com isso percebemos, de certa forma, as implicações de desvelamento e até mesmo a inversão dos papéis na comunidade de Corinto. Na Carta aos Romanos observamos a mesma advertência sobre o assunto:

Por isso Deus os entregou a paixões aviltantes: suas mulheres mudaram as relações naturais por relações contra a natureza; igualmente os homens, deixando a relação natural com a mulher, arderam em desejo um para com os outros praticando torpezas homens com homens e recebendo em si mesmos a paga da sua aberração (Romanos 1, 26-27).

A postura de Paulo frente a esse assunto foi de condenação e proibição para a comunidade na Capital do Império, uma vez que a moralidade do mundo grecoromano era pensada a partir da moralidade masculina. Logo, questões relacionadas à ordem da posição sexual interferiam, de acordo com esta moralidade, na conduta do homem no espaço público. Em última análise, a homossexualidade feminina não era importante, por isso, não cabia levantar sérias discussões. Em contrapartida, a visão dos cristãos sobre práticas lícitas e ilícitas tomaram outro caminho (CANTARELLA, 1998, p. 189).

Era natural para as mulheres terem cabelos longos (v.15), mas Paulo insistia que estes Ihes tinham sido dados como proteção (v. 15). Segundo Aline Rousselle (1989, p. 89), no Oriente e em Roma era costume as mulheres saírem com um véu ou um capuz cobrindo a cabeça. Durante a República, os homens poderiam se divorciar caso suas esposas saíssem com a cabeça descoberta. Plínio (Epistula 4. 19) regozijava-se ao dizer que a sua mulher ouvia-o ler: "estendendo uma orelha ávida por detrás de uma cortina". Também as estátuas da deusa Pudicícia estavam, em Roma, cobertas por um véu.

O vestuário da romana honrada, esposas, viúvas ou divorciadas, deixaria que somente fosse visto o seu rosto e nada mais. Horácio, em suas Sátiras (I, 2), faz a seguinte observação: "se quiseres experimentar um prazer interdito e, por assim dizer, 
defendido como uma praça forte, mil obstáculos surgem perante ti: guardas, liteiras, cabeleireiros, parasitas, vestidos que descem até ao chão, mantos compridos que tudo ocultam". A cortesã mostra a sua mercadoria, diz o poeta, ao passo que a mulher honrada "não se vê senão o rosto". Horácio escreveu no final da vida, num momento de maior liberdade de costumes em Roma que coincide com as leis rigorosas de Augusto contra o adultério.

É perceptível, na perícope 1 Cor 11, 2-16, que temos um reforço dos códigos que envolvem honra e vergonha, em que as noções de público e privado são evidenciadas a partir da postura das profetisas. Aqui parece residir a problemática presente na comunidade de Corinto, primeiramente porque o entusiasmo do Pentecostes e a abundância dos dons espirituais eram, aos olhos dos coríntios, a evidência de que eles já haviam iniciado uma nova existência espiritual tal como os anjos, entre os quais a diferenciação dos sexos já não era mais necessária; em segundo lugar, porque o texto referido estaria em consonância com o seu contexto cultural. Contudo, como assinalamos, era recomendado às mulheres o uso do véu em público, pois o desvelamento de sua cabeça poderia desonrar o homem - marido ou pai.

Em suma, percebemos que acerca dos temas relacionados ao celibato e ao casamento, Paulo expressa-se deliberada e abertamente em termos não só de mutualidade, mas, também, de igualdade. Paulo estava escrevendo não um tratado teológico, mas sim uma carta prática e de cunho pastoral. $O$ assunto central não era a igualdade ou a desigualdade entre homens e mulheres, mas o casamento e o celibato. Em razão disso, observamos, em 1 Coríntios 7, que Paulo trata mulheres e homens da mesma maneira. $\mathrm{O}$ que $\mathrm{O}$ apóstolo diz a respeito das mulheres também se aplica aos homens, e vice-versa; o que é certo para um sexo também o é para o outro.

\section{Referências}

\section{Documentação primária impressa}

BÍBLIA DE JERUSALÉM. São Paulo: Paulus, 1994.

HORÁCIO. Sátiras. Traduções de Antônio de Castilho Seabra e Antônio Feliciano de Castilho. Rio de Janeiro: W. M. Jackson, 1949. 
MARCIAL. Epigramas. Tradução Luiz Antônio de Figueiredo e Ênio Aloiso Fonda. São Paulo: Expressão Timbre, 1986.

PLINY, YOUNGER. Letters and Panegirycus. Translated by Betty Radice. Cambridge, Massachusetts: Harvard University Press, 1969.

\section{Obras de apoio}

ARAÚJO, A. D. Anjos vigilantes e mulheres desveladas: uma relação possível em 1 Cor 11,10? Orácula, v. 4.8, p. 1-41, 2008.

BARTH, K. Introdução à teologia evangélica. São Leopoldo: Sinodal, 2009.

BAUR, F. C. The Church history of the first three centuries. London: Willian \& Norgate, 1878.

CANTARELLA, E. Passato prossimo: donne romane da Tacita a Sulpicia. Milano: Feltrinelli, 1998.

DUNN, J. D. G. A teologia do apóstolo Paulo. São Paulo: Paulus, 2003.

ERHMAN, B. D. Pedro, Paulo e Maria Madalena. Rio de Janeiro: Record, 2008.

FIORENZA, E. S. Em memória dela: as origens cristãs a partir da mulher. São Paulo: Paulus, 1992.

HAWTHORNE, G. F.; MARTIN, R. P.; REID, D. G. (eds.). Dictionary of Paul and his letters: a compendium of contemporary biblical scholarship. Illinois: Intervarsity Press, 1993.

LIDDELL, H. G.; SCOTT, R. Greek-english lexicon: with a revised supplement. Oxford: Clarendon Press, 1996.

MACDONALD, D. R., Early christian women and pagan opinion: the power of the hysterical woman. New York: Cambridge University Press, 1996.

MACDONALD, D. R.; CLANTON JR., D. There is no male and female. $H D R$, n. 20, 1986.

MARTIN, R. P.; DAVIDS, P. H. (eds.). Dictionary of the later New Testament \& its developments: a compendium of contemporary biblical scholarship. Illinois: Intervarsity Press, 1997.

MURPHY-O'CONNOR, J. Sex and logic in 1 Corinthians 11, 2-16. Catholic Biblical Quarterly, v. 42, n. 4, 1980. 
ROUSSElLE, A. Pornéia: amor e sexualidade no Mundo Antigo. São Paulo: Brasiliense, 1984.

SCROGGS, R. Paul and the eschatological woman. J.A.A.R., v. 40, p. 283-303, 1972. 